\title{
Mycoplasma pneumoniae infection
}

\section{A follow-up study of 50 children with respiratory illness}

\author{
JACQUELINE Y. Q. MOK, PETER R. WAUGH, AND HAMISH SIMPSON
}

The Royal Hospital for Sick Children, Edinburgh, and

Department of Child Life and Health, University of Edinburgh

SUMMARY Fifty children with a previous history of Mycoplasma pneumoniae respiratory tract infection were assessed clinically, and pulmonary function tests carried out after an interval ranging from $1 \frac{1}{2}$ to $9 \frac{1}{2}$ years (median $2 \frac{1}{2}$ ). 23 suffered from recurrent wheezy bronchitis or asthma, and in 5 the index illness appeared to precipitate the wheezing tendency. All were symptom-free when respiratory function tests were performed. Simple tests of ventilatory function (PEFR, FEV, and FVC) were within normal limits. Increased bronchial reactivity after exercise (a fall in PEFR $>15 \%$ resting value) was demonstrated only in children known to have asthma. Maximum expiratory flow rates in air at $50 \%$ of vital capacity $\left(\dot{\mathrm{V}} \max _{50}\right)$ were within the normal range in all patients with the exception of two. The response in flow rate at $50 \%$ of vital capacity after inhalation of an $80 \%$ helium and $20 \%$ oxygen mixture $\left(\triangle \dot{\mathrm{V}} \max _{50}\right)$ was reduced $(\mathrm{P}<0.001)$ in asymptomatic patients with a history of $M$. pneumoniae respiratory infection, when compared with normal data from 48 healthy schoolchildren without a background of significant respiratory illnesses. These findings indicate impairment of small airways function, even in totally symptom-free children in the study group.

The clinical manifestations of Mycoplasma pneumoniae infection in children have been extensively reviewed (Baernstein et al., 1965; Glezen et al., 1967; Fernald et al., 1975; Stevens et al., 1978; Mok et al., 1979). The clinical course of infections caused by this organism is usually self-limiting whether or not the child has had an effective antibiotic. Studies of pulmonary function after $M$. pneumoniae infection in adults show functional abnormalities both in the acute stage (Dierckx and Gillard, 1976) and after clinical and radiological recovery (Berven, 1962). In children with respiratory symptoms studies have been confined to the acute phase of illness (Kjellman, 1976), and we have been unable to find information on pulmonary function status after clinical and radiological recovery. We report here our findings in 50 children with proved $M$. pneumoniae infection studied $1 \frac{1}{2}$ to $9 \frac{1}{2}$ years (median $2 \frac{1}{2}$ ) after their index respiratory illnesses.

Royal Hospital for Sick Children, Edinburgh

HAMISH SIMPSON, consultant paediatrician

PETER R. WAUGH, medical laboratory scientific officer

Department of Child Life and Health, University of

Edinburgh

JACQUELINE Y. Q. MOK, research fellow

\section{Patients and methods}

Patients. The names of all children admitted to the Royal Hospital for Sick Children in Edinburgh with $M$. pneumoniae infection during the period from January 1968 to December 1975 were obtained from the records of the Regional Virus Laboratory in Edinburgh. The case records of 103 children were then traced and analysed. 87 with respiratory illnesses were chosen for further follow-up study. Letters were sent to their parents requesting cooperation. Of 57 replies received, 5 declined and 2 did not attend for study. We did not attempt to trace the remaining 30 patients.

Fifty children ( 20 girls and 30 boys) aged 0.4 to $11 \cdot 3$ years (median 4 ) at the time of the index illness were studied after an interval of $1 \frac{1}{2}$ to $9 \frac{1}{2}$ years (median $2 \frac{1}{2}$ ). Chest $x$-rays obtained during the acute phase of illness showed pneumonic consolidation in 19 (16 involving one lobe and 3 more than one lobe), patchy infiltration in 19 (unilateral in 8 and bilateral in 11 ), and hyperinflation in 2 . In the 10 remaining patients with normal chest $x$-rays, cough was the main presenting symptom. 
Plan of investigation. A clinical questionnaire on each child was completed by one of us (J.Y.Q.M.). Any history of a previous respiratory illness (acute bronchiolitis, whooping cough, pneumonia, measles or chickenpox with chest involvement, or tuberculosis) and/or ongoing symptoms (cough, wheeze, breathlessness, or sputum production) before or after the index illness was noted. Each child was then examined and respiratory function tests carried out in those old enough to co-operate.

With the patient standing, peak expiratory flow rate (PEFR) was measured using the Wright's peak flow meter (Wright and McKerrow, 1959). The best of 3 attempts was accepted. Forced expiratory volume in one second $\left(\mathrm{FEV}_{1}\right)$ and forced vital capacity (FVC) were measured using the Vitalograph spirometer, and the $\mathrm{FEV}_{1} / \mathrm{FVC}$ ratio calculated.

Maximum expiratory flow volume (MEFV) curves were obtained breathing air followed by an $80 \%$ $\mathrm{He} / 20 \% \mathrm{O}_{2}$ mixture. Each child was seated and breathed quietly through a mouthpiece and an attached Lloyd valve. The subject exhaled to residual volume and then performed 3 vital capacities (VC), first breathing air and then the $\mathrm{He} / \mathrm{O}_{2}$ mixture. During the 3rd VC manoeuvre, the child expired forcibly and completely into a 'bag and box' arrangement. Displaced air passed through a flow meter (Mercury Electronics, Scotland Ltd, Glasgow). A linear relationship between flow and output voltage was achieved electronically (Tau Electronics Ltd, Edinburgh). Linearity was checked each week and remained remarkably constant. Volume was obtained from the linearised flow signal using an integrator (Tau Electronics Ltd, Edinburgh). The pneumotachygraph was calibrated for air flow using a rotameter (GEC-Elliott, Process Instruments Ltd,
Croydon). A volume calibration was carried out before each study using a 1-litre (BTPS) syringe. An identical volume signal was obtained for flow rates up to $500 \mathrm{l} / \mathrm{min}$. MEFV curves were obtained by displaying flow against volume on the $x-y$ coordinates of a storage oscilloscope (Tektronix Inc., Beaverton, Oregon). An electronic time marker indicated FEV $_{1}$. The curves were then photographed and analysed. Previous studies on normal children (H. Simpson, 1977, unpublished observations) had shown that observed differences between curves were independent of the order in which gases were inspired. Curves were compared when the vital capacity breathing $\mathrm{He}$ and $\mathrm{O}_{2}$ was within $5 \%$ of that obtained in air. The variables measured were $\mathrm{FEV}_{1}, \mathrm{FVC}$, maximum expiratory flow rates at $50 \%$ of VC $\left(\dot{\mathrm{V}} \max _{50}\right)$ and $25 \%$ of $\mathrm{VC}\left(\dot{\mathrm{V}} \max _{25}\right)$ for both the air and $\mathrm{He} / \mathrm{O}_{2}$ curves. The change in flow rate after inhalation of the $\mathrm{He} / \mathrm{O}_{2}$ mixture was measured at both 50 and $25 \%$ of VC ( $\Delta \dot{\mathrm{V}} \max _{50}$ and $\Delta \dot{\mathrm{V}} \max _{25}$ respectively).

Patients with a resting PEFR $>70 \%$ of predicted for height were exercised on a treadmill (Quinton Instruments, Seattle, Washington) for 6 minutes at a speed of $5 \mathrm{~km} / \mathrm{h}$ at a gradient of $20 \%$. The heart rate was measured after exercise and in each case was at least $160 / \mathrm{min}$. PEFR was measured before exercise, then immediately and at $2,5,10,15$, and 30 minutes after cessation of exercise. The percentage fall in PEFR from the resting value was then calculated (fall in PEFR/resting PEFR) $\times 100$.

\section{Results}

Clinical. An analysis of case records and clinical questionnaires showed a history of bronchiolitis,

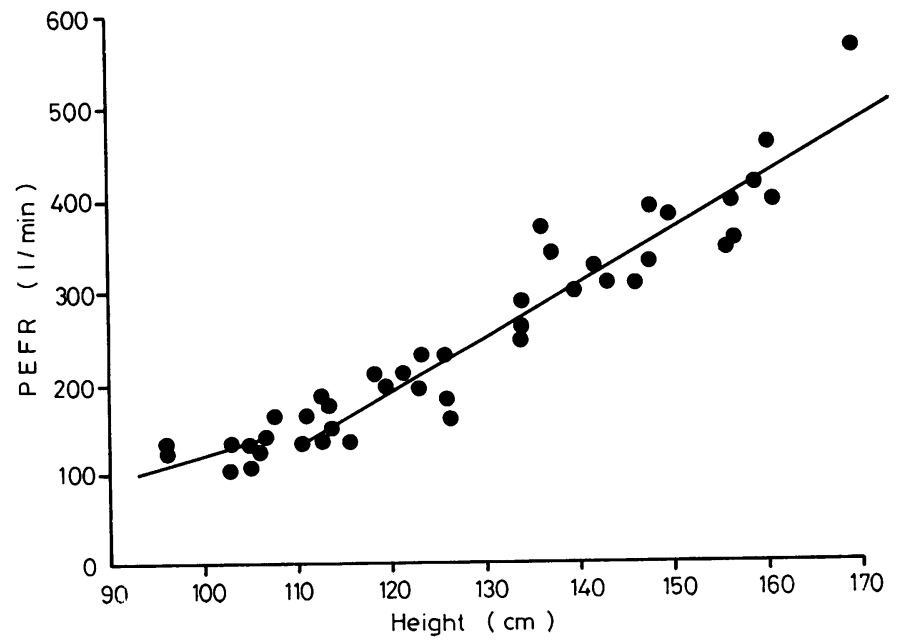

Fig. 1 Peak expiratory flow rate in 43 children with previous M. pneumoniae respiratory infection. 
pneumonia, whooping cough, measles, or chickenpox with chest involvement antedating the mycoplasma illness in 17 children. After recovery, 8 remained symptom-free. Nine had recurrent wheeziness, 8 of them since infancy. 33 children had no specific antecedent illnesses. 19 were symptom-free and 14 had a wheezing tendency which predated the index illness. Six children developed persistent cough or wheeze for the first time after the mycoplasma illness. Five of these (all with recurrent wheeze) had a strong personal or family history of atopic disorders (eczema, food allergy, allergic rhinitis).

On examination 4 children were $<10$ th centile for height and weight and 17 had mild to moderate degree of chest deformity. All patients were symptom-free and had no clinical signs of airways obstruction when respiratory function tests were performed.

Respiratory function tests. Fig. 1 gives the results of PEFR in relation to the normal data of Polgar and Promadhat (1971) and Milner and Ingram (1970). PEFR exceeded $70 \%$ of the predicted for height in all but one child. The results of FEV 1 and FVC were within normal limits, compared with the data of Polgar and Promadhat (1971). The $\mathrm{FEV}_{1} / \mathrm{FVC}$ ratio expressed as a percentage was $85 \cdot 1( \pm 7 \cdot 8)$. When patients with wheezy bronchitis or asthma were excluded this ratio was $86 \cdot 7( \pm 8 \cdot 0)$.

MEFV curves breathing air and then a $\mathrm{He} / \mathrm{O}_{2}$ mixture were obtained in 28 children. 18 had been symptom-free both before and after their index illnesses, 4 had occasional mild wheeze, and 6 were known asthmatics. The results were analysed and compared with 'normal' values obtained in 48 schoolchildren of similar heights and age range but without antecedent lower respiratory tract infections or wheezing tendency. No difference was seen with respect to $\mathrm{FEV}_{1}$ and FVC between the study and control groups.

Figs 2 and 3 show that in all but 2 patients, the results obtained for $\dot{V} \max _{50}$ and $\dot{V} \max _{25}$ were within or above the normal range for controls. Figs 4 and 5 show the results for $\Delta \dot{V} \max _{50}$ in thecontrol and nonasthmatic patients within the study groups. $\Delta \dot{\mathbf{V}} \max _{50}$ varies widely even in normal healthy children but in most cases exceeds $20 \mathrm{l} / \mathrm{min}$. Table 1 gives the mean values \pm SD for $\Delta \dot{V} \max _{50}$ and $\Delta \dot{V} \max _{25}$ in our controls and the 22 patients studied who did not have asthma. The $\triangle \dot{V} \max _{50}$ of $12 \cdot 6 \pm 13 \cdot 71 / \mathrm{min}$ in our study group differed significantly $(\mathrm{P}<0.001)$ from $24 \cdot 4 \pm 20 \cdot 8 \mathrm{l} / \mathrm{min}$ in our controls. The 22 patients included 4 in whom chest $x$-rays were normal during their index illnesses. The values for $\Delta \dot{V} \max _{50}$ in these patients were $5,10,10$, and $251 / \mathrm{min}$. When our results were reanalysed, excluding data from these patients, significance remained unaltered. There was no relation between $\Delta \dot{V} \max _{50}$ or $\Delta \dot{V} \max _{25}$ and height in either the control or study group.

Table 1 Response in flow at 25 and $50 \%$ of vital capacity after breathing a mixture of helium and oxygen $(\triangle \dot{V}$ $\max _{25}$ and $\Delta \dot{V} \max _{50}$ respectively)-actual values $\pm S D$ for control and study groups (excluding children with asthma)

\begin{tabular}{lrrl}
\hline Variable & $\begin{array}{l}\text { Control } \\
(\text { Mean } \pm S D)\end{array}$ & $\begin{array}{l}\text { Mycoplasma } \\
(\text { Mean } \pm S D)\end{array}$ & Significance \\
\hline Height $(\mathrm{cm})$ & $140.6 \pm 11.4$ & $142.9 \pm 17 \cdot 1$ & NS \\
$\triangle \dot{V} \max 25$ & $11.5 \pm 14.3$ & $8 \cdot 3 \pm 14.2$ & NS \\
$\triangle \dot{V} \max 50$ & $24.4 \pm 20.8$ & $12.6 \pm 13.7$ & P $<0.001^{*}$
\end{tabular}

*Wilcoxon test.

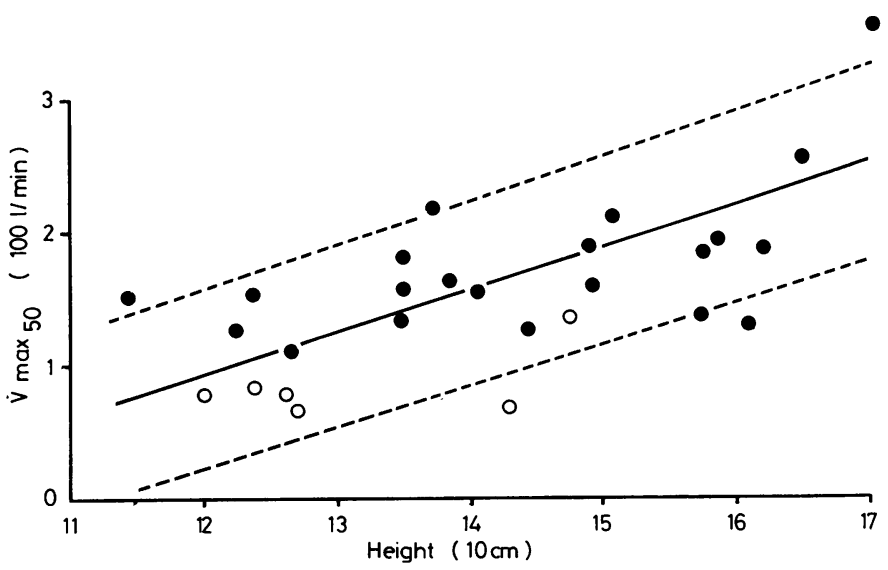

(Slope $=3 \cdot 27 \pm 0 \cdot 22$, y intercept $=-297 \cdot 8 \pm 31 \cdot 1, R=0 \cdot 73$ ). - Nonasthmatic patients O Asthmatic patients
Fig. 2 Maximum expiratory flow at $50 \%$ of vital capacity ( $\left.\dot{V} \max _{50}\right)$. Lines represent the regression and $\pm 2 S D$ for the control group of children. 


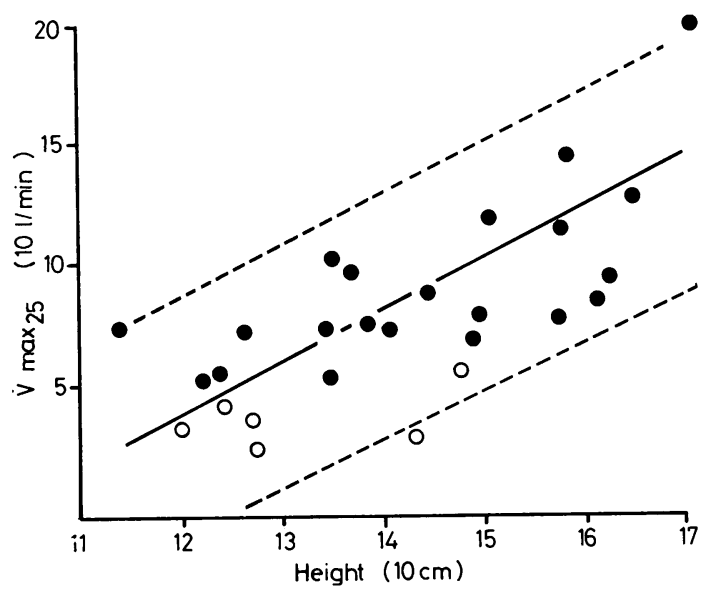

(Slope $=1.97 \pm 0 \cdot 15, y$ intercept $=-200 \cdot 5 \pm 22 \cdot 1, R=0.67)$. - Nonasthmatic patients O Asthmatic patients

Fig. 3 Maximum expiratory flow at $25 \%$ of vital capacity $\left(\dot{V} \max _{25}\right)$. Lines represent the regression and $\pm 2 S D$ for the control group of children.

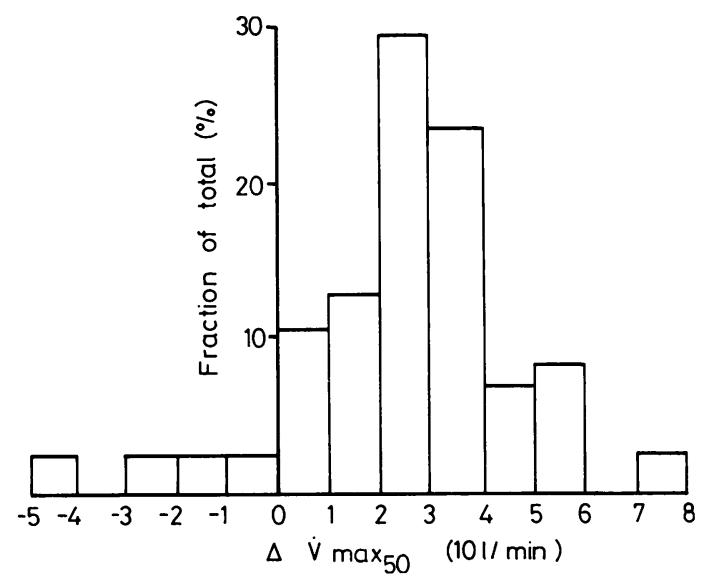

Fig. 4 Response in flow at $50 \%$ of vital capacity after breathing a mixture of helium and oxygen $\left(\triangle \dot{V} \max _{50}\right)-$ control group of children.

Table 2 summarises the results of the exercise study obtained in 34 patients. Of the remaining 16 , 14 were preschool children who could not be persuaded to perform the test, one had a PEFR less than $70 \%$ of predicted, and another withdrew from the test after 2 minutes of exercise. 20 children showed a normal response to exercise, namely a fall in PEFR in the postexercise period of $<10 \%$ of the resting value (Silverman and Anderson, 1972). The 8

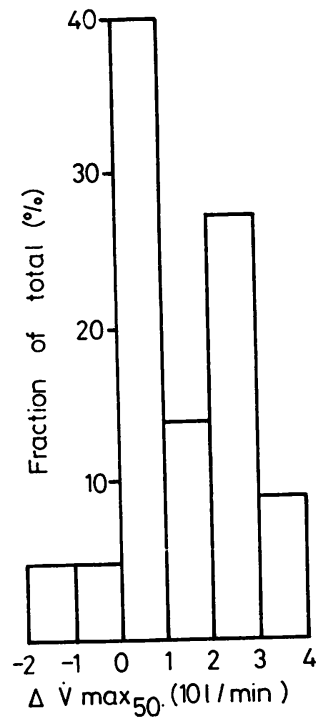

Fig. 5 Response in flow at $50 \%$ of vital capacity after breathing a mixture of helium and oxygen ( $\Delta \dot{V}$ max 50)-study group of children excluding asthmatics.

Table 2 Exercise test in 34 children

\begin{tabular}{llll}
\hline Ongoing symptoms $(\%)$ & \multicolumn{3}{l}{ Fall in PEFR } \\
\cline { 2 - 4 } & $<10$ & $10-15$ & $>15$ \\
\hline None & 16 & 5 & 0 \\
Wheeze/cough & 4 & 1 & 8 \\
Total & 20 & 6 & 8 \\
\hline
\end{tabular}

children with a fall in PEFR $>15 \%$ of the preexercise value were known asthmatics in whom a wheezing tendency antedated their mycoplasma illnesses. One of the remaining 6 children with a fall in PEFR of between 10 and $15 \%$ after exercise had only minor symptoms.

\section{Discussion}

Our results show that after clinical and radiological recovery from $M$. pneumoniae respiratory tract infection in children, routine tests of ventilatory function do not show abnormality, although the series included 10 children with wheezy bronchitis and 13 with asthma in remission at the time of study. Kjellman (1976) reported a decrease in $\mathrm{FEV}_{1}$ and FVC in children with $M$. pneumoniae pneumonia during the acute phase of their illness, which returned to normal within a week. However, distribution of ventilation, assessed by ${ }^{133} \mathrm{Xe}$ radiospirometry, remained abnormal for a longer period and in one of 9 children persisted several months later. 
Mycoplasma chest infection may be associated with wheeze in otherwise normal children, or may precipitate wheeze in those with a wheezing tendency (Berkovich et al., 1970). Our series had a high proportion of children with wheezy bronchitis or asthma, including 5 patients who developed wheeze for the first time after the index illness. It seems likely that they would have developed asthma, for each had a strong background history of atopy.

The importance of exercise studies in showing increased bronchial reactivity and thus an asthmatic tendency has been demonstrated both in normal and asthmatic children (Godfrey, 1974). Our patients who had a fall in PEFR after exercise $>15 \%$ of the preexercise value were known to have asthma and had been shown previously to have reversible airways obstruction. Sims et al. (1978) demonstrated bronchial hyper-reactivity in children 8 years after recovery from respiratory syncytial virus bronchiolitis in infancy, but they were careful not to infer a cause and effect relationship, but rather suggested that an environmental factor (low socioeconomic status or parental smoking) was the most likely link between respiratory infection in infancy and subsequent respiratory symptoms. Three of our 34 patients who did the exercise test gave a history of bronchiolitis in infancy from which they had recovered without further symptoms. All showed a normal response to exercise. It seems therefore that abnormal bronchial reactivity in our present series was due to including children with coexistent asthma and was not the result of antecedent bronchiolitis or the index mycoplasma respiratory illness.

It is now apparent that considerable obstruction of peripheral airways of the lung may be present before routine tests of ventilatory function show any abnormality. As a result there has been a search for new tests of lung function which are simple and sensitive (Macklem, 1972). One such test is based on a comparison of MEFV curves with the subject breathing air followed by an $80 \% \mathrm{He} / 20 \% \mathrm{O}_{2}$ mixture (Dosman et al., 1975). We have shown an impaired response to the inhalation of this mixture at $50 \%$ of VC in a group of asymptomatic nonasthmatic children with a history of $M$. pneumoniae chest infection. It might be argued that equilibration with helium was incomplete after $3 \mathrm{VC}$ manoeuvres. However, Dosman et al. (1975) demonstrated in symptom-free adults with normal values for routine ventilatory function tests that 3 successive VC manoeuvres were adequate to ensure equilibration with helium. This method gave results comparable with those obtained by Despas et al. (1972). We assumed that this was also true in our patients. The response to breathing the $\mathrm{He} / \mathrm{O}_{2}$ mixture was also less than in controls at $25 \%$ of vital capacity but the difference was not significant (Table 1). Impairment of response is more likely to reflect events in peripheral airways the closer to residual volume that measurements are made. However, the methodological difficulty of measuring low flow rates accurately, especially changes in flow rate, increases greatly in this part of the flow-volume curve. This may explain, at least in part, the wide range of values for $\dot{\mathrm{V}} \max _{25}$ breathing air in both control and index cases, and account for the $\Delta \dot{V} \max _{25}$ being less discriminating an index of small airways dysfunction than $\triangle \dot{V} \max _{50}$ in the present series.

Our control data were obtained from schoolchildren attending a state primary school which served a community with children from differing socioeconomic backgrounds. Our patients were similarly drawn from varied social backgrounds. A social bias in the selection of controls is unlikely, although no attempt was made to match precisely the study and control groups of children on this basis. In our analysis of MEFV curves (Table 1) we excluded children with a background history of asthma. Thus no patient in either group had significant respiratory symptoms. We conclude therefore that impairment of response in flow rate at $50 \%$ of $\mathrm{VC}$ to the $\mathrm{He} / \mathrm{O}_{2}$ mixture was due to preceding $M$. pneumoniae respiratory infection. It is not possible to say whether the impairment of function represents permanent residual lung damage or whether these children are at risk of chronic obstructive airways disease in later life.

We thank the Cystic Fibrosis Research Trust and the Lothian Health Board for generous financial support, and Mrs D. Tervit for secretarial assistance.

\section{References}

Baernstein, H. D., Trevisani, E., Axtell, S., and Quilligan, J. J. (1965). Mycoplasma pneumoniae (Eaton atypical pneumonia agent) in children's respiratory infections. Journal of Pediatrics, 66, 829-837.

Berkovich, S., Millian, S. J., and Snyder, R. D. (1970). The association of viral and mycoplasma infections with recurrence of wheezing in the asthmatic child. Annals of Allergy, 28, 43-49.

Berven, H. (1962). Studies on the cardiopulmonary function in the post-infectious phase of 'atypical' pneumonia. Acta medica Scandinavica, Supplement 382, 1-78.

Despas, P. J., Leroux, M., and Macklem, P. T. (1972). Site of airway obstruction in asthma as determined by measuring maximal expiratory flow breathing air and a $\mathrm{He}^{-\mathrm{O}_{2}}$ mixture. Journal of Clinical Investigation, 51, 3235-3243.

Dierckx, J. P., and Gillard, C. (1976). The results of pulmonary function tests in patients infected with Mycoplasma pneumoniae. Infection, 4, Supplement 1, 68-70.

Dosman, J., Bode, F., Urbanetti, J., Martin, R., and Macklem, P.T. (1975). The use of a helium-oxygen mixture 
during maximum expiratory flow to demonstrate obstruction in small airways in smokers. Journal of Clinical Investigation, 55, 1090-1099.

Fernald, G. W., Collier, A. M., and Clyde, W. A., Jr (1975). Respiratory infections due to Mycoplasma pneumoniae in infants and children. Pediatrics, 55, 327-335.

Glezen, W. P., Thornburg, G., Chin, T. D., and Wenner, H. A. (1967). Significance of mycoplasma infections in children with respiratory disease. Pediatrics, 39, 516-525.

Godfrey, S. (1974). Exercise Testing in Children. Applications in Health and Disease. Saunders: Philadelphia.

Kjellman, B. (1976). Pulmonary function in children with Mycoplasma pneumoniae pneumonia. Infection, 4, Supplement 1, 71-74.

Macklem, P. T. (1972). Obstruction in small airways-a challenge to medicine. American Journal of Medicine, 52, 721-724.

Milner, A. D., and Ingram, D. (1970). Peak expiratory flow rates in children under 5 years of age. Archives of Disease in Childhood, 45, 780-782.

Mok, J. Y. Q., Inglis, J. M., and Simpson, H. (1979). Mycoplasma pneumoniae infection. A retrospective review of 103 hospitalised children. Acta medica Scandinavica. In press.

Polgar, G., and Promadhat, V. (1971). Pulmonary Function
Testing in Children. Techniques and Standards. Saunders: Philadelphia.

Silverman, M., and Anderson, S. D. (1972). Standardisation of exercise tests in asthmatic children. Archives of Disease in Childhood, 47, 882-889.

Sims, D. G., Downham, M. A. P. S., Gardner, P. S., Webb, J. K. G., and Weightman, D. (1978). Study of 8 year old children with a history of respiratory syncytial virus bronchiolitis in infancy. British Medical Journal, 1, 11-14.

Stevens, D., Swift, P. G. F., Johnston, P. G. B., Kearney, P. J., Corner, B. D., and Burman, D. (1978). Mycoplasma pneumoniae infections in children. Archives of Disease in Childhood, 53, 38-42.

Wright, B. M., and McKerrow, C. B. (1959). Maximum forced expiratory flow rate as a measure of ventilatory capacity with the description of a new portable instrument for measuring it. British Medical Journal, 2, 1041-1047.

Correspondence to Dr H. Simpson, Department of Child Life and Health, 17 Hatton Place, Edinburgh EH9 1UW.

Received 7 November 1978 